EGU21-13520

https://doi.org/10.5194/egusphere-egu21-13520

EGU General Assembly 2021

(c) Author(s) 2022. This work is distributed under

the Creative Commons Attribution 4.0 License.

\title{
SubSpread: An integrated approach to understand the signature, mechanics and controls of subaqueous spreading
}

\author{
Monica Giona Bucci ${ }^{1}$, Aaron Micallef ${ }^{1,2}$, Morelia Urlaub ${ }^{2}$, and Joshu Mountjoy ${ }^{3}$ \\ 1'L-Università ta\&\#39; Malta, Geosciences, MSIDA, Malta (monica.giona-bucci@um.edu.mt) \\ ${ }^{2}$ GEOMAR, Helmholtz Centre for Ocean Research Kiel \\ ${ }^{3}$ NIWA, Climate, Freshwater \& Ocean Science
}

Subaqueous spreading is a widespread type of mass movement, which involves extensional displacement along a gliding plane and the deformation of the failing layer into a sequence of ridges and troughs. Spreading has been poorly investigated, nonetheless it poses hazard to offshore infrastructures. SubSpread is a new project that will investigate the mechanics of the spreading failure and its geological controls in the subaqueous environment. The first objective of SubSpread is to identify the topographic and sedimentary signature of subaqueous environment. We have compiled a global database of subaqueous and subaerial spreads that includes information on physiography, geomorphology, sedimentology and geotechnical properties, where available. A preliminary analysis of the database reveals that spreading morphologies occur on both passive and active margins, especially in the headwall area of translational retrogressive slides. Potential causes of spreading include seismic loading (also glacially induced), sediment loading, and increased pore pressure generated by migration of fluid or gas. The latter may induce loss of shear strength and the formation of a weak layer, particularly in gentle open slopes. Information compiled in this database will also be used to develop a numerical model that can better understand the mechanics and rheological aspects of submarine spreading, focusing on the role played by pore pressure generation. The Tuaheni slide complex in the Hikurangi Margin of New Zealand is being used as a case-study in view of the wealth of geophysical and sedimentological data that are available. The final part of the SubSpread project will test whether the morphometric and sedimentological signature of spreading can provide information on past seismicity. In this case, the test site will be Lake Tekapo in the South Island of New Zealand. 